\title{
High Output Heart Failure 8 Months After an Acquired Arteriovenous Fistula
}

\author{
Murtaza Emre DuraKoglugIL, ${ }^{1} \mathrm{MD}$, Mehmet Gungor KAYA, ${ }^{1} \mathrm{MD}$, \\ Bulent BOYACI, ${ }^{1} \mathrm{MD}$, and Atiye CENGEL, ${ }^{1} \mathrm{MD}$
}

\begin{abstract}
SUMMARY
Congestive heart failure (CHF) due to hyperkinetic states can occur in systemic diseases and in arteriovenous fistulas. An 18 year old Turkish male patient complaining of dyspnea and palpitations, who had suffered a stab wound to his abdomen eight months earlier, was admitted to our clinic. Auscultation revealed a systolodiastolic murmur over the entire abdomen. Chest $\mathrm{x}$-rays demonstrated significant cardiomegaly. Echocardiography revealed biatrial enlargement and significant mitral and tricuspid regurgitation accompanied by dilatation of the inferior vena cava. Right heart catheterization showed increased oxygen saturation at the inferior vena cava. A diagnosis of an aortocaval fistula was made by aortography. The symptoms subsided and valvular regurgitations ceased after surgical correction. This rare case demonstrates the significance of routine physical examination and history of the patient. (Jpn Heart J 2003; 44: 805-809)
\end{abstract}

Key words: High output heart failure, Aortocaval fistula

HYPERKINETIC heart failure may occur as a result of arteriovenous fistulas and systemic illnesses such as hyperthyroidism, wet beriberi, and Paget's disease of the bone. Arteriovenous fistulas due to arteriovenous malformations, iatrogenic interventions (dialysis fistulas, nephrectomy, arterial puncture), and trauma (blunt, penetrating) have been described. Systolodiastolic murmurs, development of varicose veins, and cardiac chamber enlargement may be the earliest findings. Late complications like thrombosis and pseudoaneurysm may arise in the dilated part of the central artery. Herein we report an aortocaval fistula as the etiology of congestive heart failure in a 18 year old man with a previous stab wound in the abdomen.

From the ${ }^{1}$ Department of Cardiology, School Of Medicine, Gazi University, Ankara, Turkey.

Address for correspondence: Emre Durakoglugil, MD, Gazi Universitesi Hastanesi, Kardiyoloji, Anabilim Dali, 06500, Ankara, Turkey.

Received for publication November 18, 2002.

Revised and accepted March 16, 2003. 


\section{Case Report}

An 18 year old Turkish male patient was admitted to our cardiology clinic with complaints of dyspnea and palpitations lasting for six months. His previous medical history was not significant except for a small bowel resection because of a stab wound eight months earlier. No official report about a vascular injury was available.

During physical examination, tachycardia (110/min), widened pulse pressures, a third heart sound, and a systolodiastolic murmur over the abdomen were found. Thrill was present at the femoral arteries. Neither rales nor rhonchi were present. Laboratory tests including complete blood cell counts, coagulation parameters, thyroid function tests, serum electrolytes and liver function tests were within normal limits. Electrocardiography showed sinus tachycardia. Chest x-rays demonstrated cardiomegaly. Transthoracic echocardiography demonstrated a hyperdynamic left ventricle with an estimated ejection fraction of $63 \%$. Right heart cavities were significantly enlarged and the left atrium was dilated. Left ventricular end-diastolic diameter was within the upper range. The subcostal view showed dilatation of the inferior caval vein. Mild mitral regurgitation, severe tricuspid regurgitation, and a maximum pulmonary artery pressure of 65 $\mathrm{mmHg}$ were detected by color Doppler. Right and left heart catheterization revealed a pulmonary capillary wedge pressure of $18 \mathrm{mmHg}$, a right atrial pressure of $8 \mathrm{mmHg}$, a right ventricular pressure of $38 / 11 \mathrm{mmHg}$, and a pulmonary artery pressure of $35 / 12 \mathrm{mmHg}$. Oxygen saturations of $93 \%$ in the left ventricle, $84 \%$ in the right atrium, $83 \%$ in the right ventricle, $82 \%$ in the pulmonary artery, $71 \%$ in the superior vena cava, and $93 \%$ in the inferior cava were detected. Abdominal aortography demonstrated a high flow aortocaval fistula and a proximal pseudoaneurysm in the left common iliac artery (Figures 1 and 2).

Transarterial embolization (TAE) was the preferred method because of the previous abdominal surgery and possible fibrosis. Corrective surgical treatment was undertaken after an unsuccessful attempt at TAE. The patient had minimal symptoms two months later. Control echocardiography revealed only minimal mitral and tricuspid regurgitation, with normal chamber sizes (Table).

Table. Echocardiographic Chamber Diameters at Onset and Two Months Later

\begin{tabular}{lll}
\hline Chamber diameter & Onset & Two months later \\
\hline Left ventricle end-diastolic diameter & $5.7 \mathrm{~cm}$ & $5.3 \mathrm{~cm}$ \\
Left ventricle end-systolic diameter & $3.7 \mathrm{~cm}$ & $3.6 \mathrm{~cm}$ \\
Ejection fraction (EF) & $63 \%$ & $60 \%$ \\
Left atrium & $5.5 \mathrm{~cm}$ & $3.4 \mathrm{~cm}$ \\
Right atrium & $6.5 \mathrm{~cm}$ & $4.4 \mathrm{~cm}$ \\
Right ventricle & $4.9 \mathrm{~cm}$ & $3.8 \mathrm{~cm}$ \\
\hline
\end{tabular}




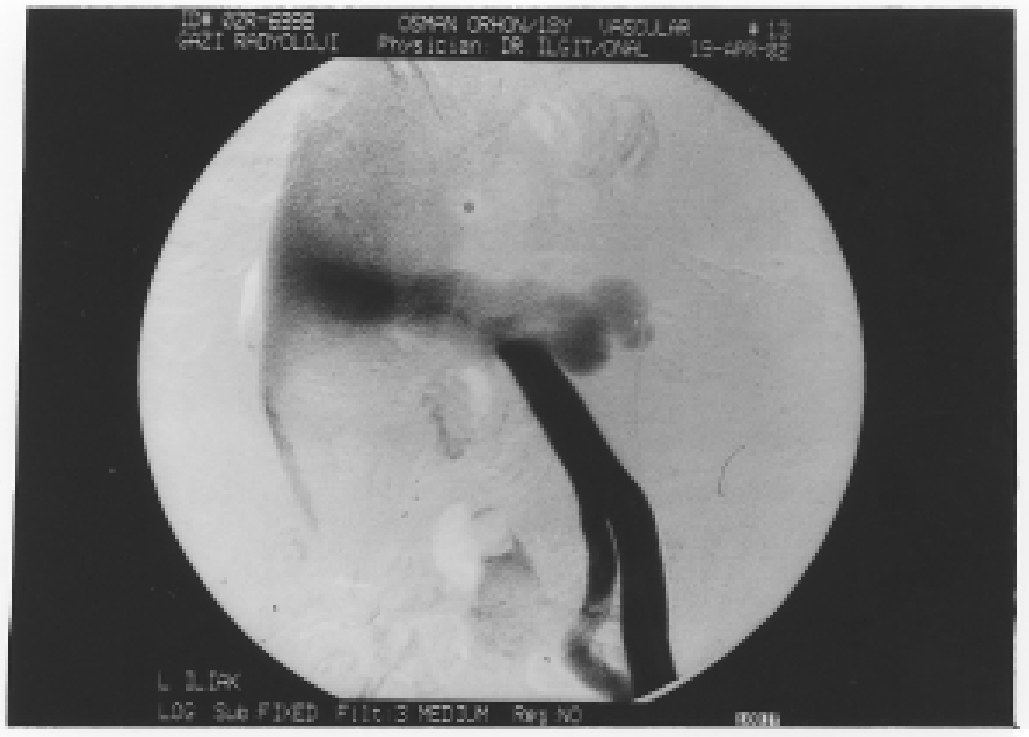

Figure 1. Aortography demonstrating aortocaval fistula originating from left common iliac artery.

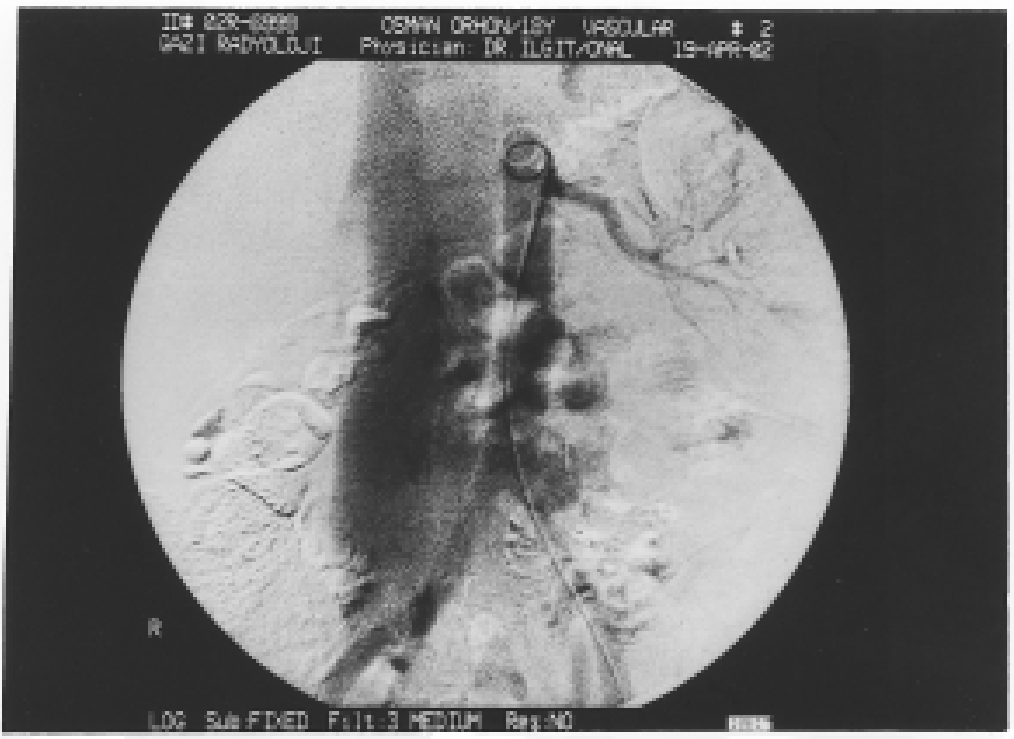

Figure 2. Aortography demonstrating radiocontrast filled inferior vena cava after intra-aortic injection. 


\section{DISCUSSION}

Arteriovenous fistulas are among the rare causes of CHF. Hyperkinetic heart failure may occur in arteriovenous fistulas and as a result of systemic diseases including severe anemia, wet beriberi, hyperthyroidism, malignancies, and Paget's disease of the bone. Invasive procedures (arterial punctures, percutaneous renal biopsy), surgical procedures (laminectomy, ${ }^{1-2)}$ nephrectomy ${ }^{3)}$ ), and trauma may result in arteriovenous fistulas. When heart failure of uncertain etiology appears in patients previously submitted to one of the above mentioned procedures, a careful clinical examination can lead to the diagnosis of iatrogenic arteriovenous fistula. Increased pulse pressure, a palpable pulsatile mass, murmur and thrill over the scars, a positive Branham sign, and development of varicose veins at the affected extremity are the major clinical findings. Increased cardiac output and volume overload will lead to CHF eventually. The primary factors determining heart failure are the magnitude of the shunt and decreased systemic vascular resistance. The onset of CHF as long as 63 years after a trauma has been described in the literature. ${ }^{1-6)}$ Our patient, who had a structurally normal heart, developed high output heart failure 8 months after establishment of the fistula. This short period differs from other patients and shows the significance of the shunt. Commonly signs of CHF disappear after surgery but irreversible heart failure occurred in one patient due to a bilateral hemodialysis fistula. ${ }^{7)}$ Our patient had minimal symptoms two months after surgical treatment. Treatment is mainly surgical, with TAE becoming increasingly common. ${ }^{8,9)}$

To our knowledge, many arteriovenous fistulas presenting with $\mathrm{CHF}$ are found in the elderly population. Our patient was an 18 year old male with the complaint of dyspnea. The most important clues for a correct diagnosis were the increased pulse pressure, systolodiastolic murmur, thrill, echocardiographic dilation of the inferior vena cava, in addition to the history of trauma. Congenital heart diseases, like venous return abnormalities, were also suspected because of the dilated cardiac chambers and inferior vena cava. Echocardiography, an important diagnostic tool in $\mathrm{CHF}$, has been shown to be helpful for revealing etiology by demonstrating a dilated caval vein and turbulent vascular flow in the subcostal view with color Doppler by Abreo, et al. ${ }^{5)}$ We also demonstrated a dilated inferior caval vein in the subcostal view. This rare case emphasizes the role of careful physical examination and echocardiography in a cardiac patient with a suspected arteriovenous fistula. 


\section{REFERENCES}

1. Pereira H, Cotrim I, Abreu A, et al. Heart failure due to a postlaminectomy arteriovenous fistula. Rev Port Cardiol 1995; 14: 579-82.

2. Stellbrink C, Kunze KP, Lambertz H, Urhahn R, Hanrath P. An iatrogenic arteriovenous fistula following laminectomy. A rare differential diagnosis of heart failure.: Dtsch Med Wochenschr. 1991; 116: 1141.

3. Hirai S, Hamanaka Y, Mitsui N, Kumagai H, Nakamae N. High-output heart failure caused by a huge renal arteriovenous fistula after nephrectomy: report of a case. Surg Today 2001; 31: 468-70.

4. Turgeman Y, Rosenfeld T. Severe left heart failure long after acquired arteriovenous fistula. Harefuah 1989; 116: 41-43.

5. Abreo G, Lenihan DJ, Nguyen P, Runge MS. High-output heart failure resulting from a remote traumatic aortocaval fistula: diagnosis by echocardiography. Clin Cardiol 2000; 23: 304-6.

6. Frishman W, Epstein AM, Kulick S, Killip T. Heart failure 63 years after traumatic arteriovenous fistula. Am J Cardiol 1974; 34: 733-6.

7. Ingram CW, Satler LF, Rackley CE. Progressive heart failure secondary to a high output state. Chest 1987; 92 : 1117-8.

8. Wang KT, Hou CJ, Hsieh JJ, Chou YS, Tsai CH. Late development of renal arteriovenous fistula following gunshot trauma--a case report. Angiology 1998; 49: 415-8.

9. Portela A, Bastos R, Pessoa B, Duarte R, Medeiros M, Paiva J. Remission of heart failure through endoluminal repair of femoral arteriovenous fistula with the use of a covered stent. Arq Bras Cardiol 2001; 76: 239-4. 